\title{
FVIIa corrects the coagulopathy of fulminant hepatic failure but may be associated with thrombosis: a report of four cases
}

\author{
[Le FVIIa corrige la coagulopathie d'une insuffisance hépatique fulminante, \\ mais peut être associé à la thrombose : présentation de quatre cas]
}

Patricia Pavese MD, ${ }^{*}$ Agnès Bonadona MD, ${ }^{*}$ Jean Beaubien MD, $†$ Pascal Labrecque MD, $†$ Gilles Pernod MD, $\ddagger$ Christian Letoublon MD, $\$$ Didier Barnoud $\mathrm{MD}^{*}$

\begin{abstract}
Purpose: During liver transplantation, excessive blood losses are correlated with increased morbidity and mortality. Blood losses are particularly high in the case of urgent liver transplantation for fulminant hepatic failure (FHF). Recombinant activated factor VII ( $r F V I l a)$ has shown promise in treating the coagulopathy of liver disease. We review our experience with the use of rFVlla in treating the coagulopathy of FHF during urgent liver transplantation.
\end{abstract}

Clinical features: We report four patients with FHF who met King's College criteria for liver transplantation and in whom rFVIla was used after conventional means for treating the associated coagulopathy had failed. In all patients, the coagulation defect was corrected by rFVlla. However, thrombotic complications occurred in two patients (myocardial ischemia and portal vein thrombosis) and the implication of rFVlla cannot be excluded.

Conclusion: We conclude that rFVlla is effective in the correction of the coagulopathy associated with FHF. However, thrombotic events are of concern and therefore, further studies are warranted to define the safety of rFVlla in that setting.

Objectif : Pendant la transplantation hépatique, d'importantes pertes sanguines entraînent une hausse de la morbidité et de la mortalité. Ces pertes sont particulièrement élevées lors d'une transplantation d'urgence pour insuffisance hépatique fulminante (IHF). Le facteur VII recombiné activé (rFVIla) s'est montré prometteur contre la coagulopathie de la lésion hépatique. Nous passons en revue notre expérience de l'usage du rFVIla pour traiter la coagulopathie de l'IHF pendant la transplantation hépatique d'urgence.

Éléments cliniques : Nous présentons quatre patients atteints d'IHF qui répondaient aux critères du King's College pour la transplantation hépatique et chez qui le rFVIla a été utilisé après l'échec du traitement traditionnel de la coagulopathie associée. Le rFVIla a corrigé le défaut de coagulation chez tous les patients. Cependant, deux patients ont subi des complications thrombotiques (ischémie myocardique et thrombose de la veine porte) pour lesquelles l'implication du rFVIla ne peut être exclue.

Conclusion : Le rFVIla est efficace pour corriger la coagulopathie associée à l'IHF. Néanmoins, les événements thrombotiques sont préoccupants et appellent à la réalisation d'autres études pour définir l'innocuité du rFVIla dans ce contexte.

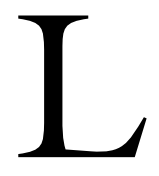

IVER transplantation has undergone remarkable advances since the first human liver transplantation by Starzl in 1963. The procedure has now progressed to become the treatment of choice for patients with acute or chronic end-stage liver disease. Although advances in anesthetic and surgical techniques have reduced the too frequent occurrence of massive perioperative massive blood loss of the early days, ${ }^{1}$ liver transplantation remains a challenging surgery in this regard. Even if a significant intercentre heterogeneity in transfusion therapy is known, the overall median number of red blood cell units transfused for an orthotopic liver transplantation (OLT) is five. ${ }^{2}$ A recently published pilot study reported reduced transfusion requirements with recombinant factor VIIa (rFVIIa) in OLT $^{3}$ and, lately, the efficacy of rFVIIa in the correction of the coagulopathy usually seen in fulminant hepatic failure (FHF) has been established. ${ }^{4}$ 
It has even been suggested that rFVIIa could be a universal hemostatic agent. ${ }^{5}$ Indeed, many studies have shown a clinical benefit in various hemostatic disorders and other clinical situations where hemorrhage can be an issue. Hence, aside of acquired hemophilia, the successful use of rFVIIa has been reported in cases of thrombocytopenia, ${ }^{6}$ excessive oral anticoagulation with vitamin $\mathrm{K}$ antagonists, ${ }^{7}$ trauma, ${ }^{8}$ intracerebral hemorrhage (in progress), ${ }^{9} \mathrm{FHF},{ }^{4}$ cirrhosis, ${ }^{10}$ pulmonary bleeding, ${ }^{11}$ intractable postsurgical intra-abdominal hemorrhage, ${ }^{12}$ dilutional coagulopathy following orthopedic surgery, ${ }^{13}$ and bleeding in severe necrotizing pancreatitis. ${ }^{14}$ It has also been used prophylacticaly in liver transplantation ${ }^{3}$ and radical prostatectomy. ${ }^{15} \mathrm{We}$ report our experience in four cases where we used rFVIIa to treat perioperative coagulopathy before, during or after liver transplantation.

\section{Case reports \\ Patient 1}

A 49-yr-old woman with a history of chronic normocytic hemolytic anemia presented with fulminant hepatic and renal failure. The initial prothrombin time (PT) was $126 \mathrm{sec}$ and failed to decrease below $40.6 \mathrm{sec}$ despite 45 $\mathrm{mL} \cdot \mathrm{kg}^{-1}$ of fresh frozen plasma. Because of her rapidly deteriorating clinical condition, urgent liver transplantation was requested. Hemodynamic variables were maintained with norepinephrine and dobutamine. $90 \mu \mathrm{g} \cdot \mathrm{kg}^{-1}$ of rFVIIa were administered before surgery and repeated intraoperatively two hours later. Immediately after the second dose, the PT was down to $12.6 \mathrm{sec}$ [international normalized ratio (INR) 1.0] and remained at $16.6 \mathrm{sec}$ five hours later. Transplantation was uneventful and six units of packed red blood cells (PRC) were transfused. Pathological findings suggested a Budd Chiari syndrome; a posteriori, a clinical diagnosis of paroxysmal nocturnal hemoglobinuria was confirmed by the identification of a glycosylphosphatidylinositol blood cell membrane deficit. Postoperatively, while still under norepinephrine, an elevation of troponine with segmental anterolateral hypokinesia on transoesophageal echocardiography suggested myocardial ischemia. Cardiac function completely recovered in the following days and the rest of the postoperative course was uneventful.

\section{Patient 2}

A 27-yr-old woman with cystic fibrosis and Child C cirrhosis was scheduled for elective liver transplantation, but was admitted for hepatic decompensation and hepatorenal failure. Her PT deteriorated over time and was $40.6 \mathrm{sec}$ preoperatively despite $30 \mathrm{~mL} \cdot \mathrm{kg}^{-1}$ of fresh frozen plasma. Before the urgent liver transplantation, two doses of rFVIIa $\left(90 \mu \mathrm{g} \cdot \mathrm{kg}^{-1}\right)$ were administered prophylactically, two hours apart. The PT was $12.6 \mathrm{sec}$ (INR 1.0) one hour after the second dose and remained at $26.3 \mathrm{sec} 12 \mathrm{hr}$ later. Transfusion of five units of PRC was required during the otherwise uneventful transplantation. Ten hours postoperatively, as the patient developed hemorrhagic shock, a single dose of rFVIIa was administered to control bleeding (the PT decreased from $25.7 \mathrm{sec}$ to $13.8 \mathrm{sec}$; the platelet count was normal). No thrombotic complications were observed in the following days.

\section{Patient 3}

A 59-yr-old man with no past medical history developed a FHF of toxic origin. On the computed tomography scan, no cerebral edema was present but the clinical picture included acute renal failure. The initial PT was $126.0 \mathrm{sec}$ and failed to decrease below 39.4 sec despite $60 \mathrm{~mL} \cdot \mathrm{kg}^{-1}$ of fresh frozen plasma. The patient underwent an emergency liver transplantation and received a single dose of rFVIIa $\left(90 \mu \mathrm{g} \cdot \mathrm{kg}^{-1}\right)$ before surgery. The PT decreased to $12.6 \mathrm{sec}$ and drifted to $24.2 \mathrm{sec}$ six hours later. Three units of PRC were transfused during the operation. On the day following surgery, a routine Doppler blood flow assessment of the graft revealed thrombosis of the portal vein. This proved to be rapidly reversible with iv heparin. Unfortunately, 15 days postoperatively, the patient developed a cerebral hematoma and, subsequently, fatal intracranial hypertension.

\section{Patient 4}

A 55-yr-old man with post hepatitis B cirrhosis and unifocal hepatocarcinoma underwent an uneventful liver transplantation. Two days later, as abdominal pain and refractory shock developed, a subcapsular hepatic hematoma was diagnosed radiologically. An emergency laparotomy with temporary hepatic artery clamping was realized with apparent control of the hemorrhage. Nevertheless, postoperatively, hepatic failure developed and the coagulation variables deteriorated. A second liver transplantation was performed after $24 \mathrm{hr}$ of an almost hepatic phase. Preoperatively, the PT was $37.1 \mathrm{sec}$ and failed to decrease despite aggressive transfusion therapy. Two doses of rFVIIa $\left(90 \mu \mathrm{g} \cdot \mathrm{kg}^{-1}\right)$ were given, the first one preoperatively and the second during the surgery. The PT was 12.6 sec (INR 1.0) after the second dose and identical seven hours later. Eight units of PRC were used during transplantation, no thrombotic events were observed and the patient was discharged from the intensive care unit with good hepatic function and a recovering renal function. 


\section{Discussion}

Activated factor VII is a naturally occurring initiator of hemostasis that is essential to the process of coagulation. Once an endothelial cell has been injured, tissue factor (TF) exposed at the surface of the cell interacts with a small amount of circulating activated factor VII. Activated factor VII appears to be active only in the presence of TF. The TF-FVIIa complex then allows the activation of factor $\mathrm{X}$ into Xa which induces the transformation of prothrombin into thrombin. Only a small quantity of thrombin is generated this way, but it is sufficient to activate platelets locally. This initial activation of coagulation will rapidly be inhibited by the TF pathway inhibitor. Besides its activation of factor X, the TFFVIIa complex also activates factor IX. In the presence of activated platelets, factor IXa will produce a large quantity of thrombin, thus enhancing the transformation of fibrinogen into fibrin. rFVIIa works by reinforcing this natural coagulation process and should, in theory, only have a local action at sites where TF and phospholipids are exposed. However, high levels of rFVIIa can increase the amount of thrombin generated by binding directly to activated platelets, thus having a TF independent procoagulant effect. Furthermore, a bolus injection of rFVIIa, causing a major increase in thrombin, activates the thrombin-activatable fibrinolysis inhibitor (TAFI). TAFI down-regulates fibrinolysis and promotes coagulation. ${ }^{5}$

Originally developed for patients with inhibitor induced acquired hemophilia, commercially available rFVIIa (NovoSeven) is a vitamin K-dependent glycoprotein consisting of 406 amino acid residues (MW 50 kdaltons). It is produced in a culture of baby hamster kidney cells expressing the cloned human gene for factor VII. During the chromatographic purification process, autocatalysis transforms rFVII into rFVIIa, structurally similar to human plasma derived factor VIIa and any exogenous virus is removed. No human serum or other proteins are used in the production of the formulation. rFVIIa has a half-life of less than three hours ${ }^{16}$ and, initially, the recommended dosage in hemophilia patients undergoing surgery was 90 $\mu \mathrm{g} \cdot \mathrm{kg}^{-1}$ immediately before and during the operation, and every two hours for $48 \mathrm{hr}$. There are conflicting results regarding the effectiveness of a continuous infusion as it may not be efficacious to inhibit fibrinolysis. ${ }^{17}$ Several studies have shown that surgery in hemophilia patients with high titre of inhibitors can be performed safely using rFVIIa.

The use of rFVIIa has been studied in patients with cirrhosis and shown to result in correction of the PT in all patients treated with a dosage of $90 \mu \mathrm{g} \cdot \mathrm{kg}^{-1}$. $^{3}$ Different dosages have been studied $(5,20,80$ $\left.\mu \mathrm{g} \cdot \mathrm{kg}^{-1}\right)$ and have shown a dose-dependent duration of PT correction. In the four patients described, we used the recommended dosage for hemophilia patients. Only one patient required more than two doses on clinical grounds. Our results do not allow us to determine whether repeating a second dose is useful or not. The optimal dosage of rFVIIa remains unclear in the context of liver transplantation.

A recently reported pilot study in six patients undergoing elective liver transplantation showed a significant reduction of blood loss and red cell transfusion in patients treated with a single dose of rFVIIa. ${ }^{3}$ A limitation of that study though, is the use of a historical control group; one has to consider the well known decrease in red blood cell transfusion requirements for liver transplantation over the last decade. ${ }^{1}$ In addition, in that study, patients with acute renal failure, FHF, hepatic encephalopathy and those who had received plasma transfusions were excluded. Nevertheless, in our four patients with urgent liver transplantation, red blood cell transfusion requirements compare advantageously with those of the historical control group of elective patients of that study (mean 5.5 vs 7 ).

We believe that rFVIIa can be a very useful hemostatic agent, particularly in those situations where coagulopathy greatly complicates patient management. As a recent editorial judiciously pointed out: "it would not be appropriate, at this time, to attempt to replace standard diagnostic measures and standard accepted therapy with the use of rFVIIa; when these measures truly fail, it may be reasonable to use rFVIIa as an attempted rescue thera$p y{ }^{\prime \prime} .{ }^{18}$ Accordingly, in all four patients, standard therapy to correct coagulopathy was attempted prior to using rFVIIa. In a recently published study comparing rFVIIa with conventional therapy in $\mathrm{FHF},{ }^{4}$ rFVIIa succeeded in correcting the coagulopathy more often than plasma alone, the rFVIIa group showed less anasarca and no patient suffered any adverse effect. Avoidance of anarsaca could be beneficial to those patients susceptible to cerebral edema.

In most of the studies reviewed, no adverse events were seen in patients treated with rFVIIa; more specifically, there was no increase in thrombotic events when compared to controls. ${ }^{19-22}$ Recently some authors have reported thrombotic events following therapy with rFVIIa. ${ }^{23,24}$ Patients (trauma, liver surgery) received multiple treatments, including antibrinolytics, and the exact cause of the thromboses cannot be determined. Moreover they had additional risk factors for thrombosis. Interestingly enough, in the four patients we describe, we observed two thrombotic incidents. In patient 1, myocardial ischemia appeared while the patient was under norepinephrine; even if recovery was 
complete, the implication of rFVIIa cannot be excluded. The second event, portal vein thrombosis is not uncommon shortly after liver transplantation but, again, the implication of rFVIIa cannot be excluded.

Our preliminary experience suggests that rFVIIa may be useful in the management of patients during emergency liver transplantation. However, the optimal dosing scheme remains to be established and further studies are needed to define the safety of this agent in this particular setting.

\section{References}

1 Hendricks HG, van der Meer J, Klompmaker IJ, et al. Blood loss in orthotopic liver transplantation: a retrospective analysis of transfusion requirements and the effects of autotransfusion of cell saver blood in 164 consecutive patients. Blood Coagul Fibrinolysis 2000; 11(Suppl 1): S87-93.

2 Ozier $\Upsilon$, Pessione F, Samain E, Courtois F, French study group on blood transfusion in liver transplantation. Institutional variability in transfusion practice for liver transplantation. Anesth Analg 2003; 97: 671-9.

3 Hendricks HG, Meijer K, De WolfJT, et al. Reduced transfusion requirements by recombinant factor VIIa in orthotopic liver transplantation. Transplantation 2001; 71: 402-5.

4 Shami VM, Caldwell SH, Hespenheide EE, Arseneau $K O$, Bickston SJ, Macik BG. Recombinant activated factor VII for coagulopathy in fulminant hepatic failure compared with conventional therapy. Liver Transpl 2003; 9: 138-43.

5 Hedner $U$. NovoSeven ${ }^{\circledR}$ as a universal haemostatic agent. Blood Coagul Fibrinolysis 2000; 11(Suppl 1): S107-11.

6 Poon MC, d'Oiron R. Recombinant activated factor VII (NovoSeven) treatment of platelet-related bleeding disorders. International Registry on Recombinant Factor VIIa and Congenital Platelet Disorders Group. Blood Coagul Fibrinolysis 2000; 11(Suppl 1): S55-68.

7 Berntorp E, Stigendal L, Lethagen S, Olofsson L, Hedner $U$. NovoSeven ${ }^{\circledR}$ in warfarin-treated patients. Blood Coagul Fibrinolysis 2000; 11(Suppl 1): S113-5.

8 Martinowitz U, Kenet $G$, Segal E, et al. Recombinant activated factor VII for adjunctive hemorrhage control in trauma. J Trauma 2001; 51: 431-9.

9 Mayer $S A$. Intracerebral hemorrhage: natural history and rationale of ultra-early hemostatic therapy. Intensive Care Med 2002; 28: S235-40.

10 Bernstein DE, Jeffers L, Erhardtsen E, et al. Recombinant factor VIIa corrects prothrombin time in cirrhotic patients: a preliminary study. Gastroenterology 1997; 113: 1930-7.

11 Kamphuisen PW, van den Akker JM, Kaasjager KA,
Bloemen TL. Control of life-threatening pulmonary bleeding with activated recombinant factor VII (Letter). Am J Med 2002; 112: 332-3.

12 White B, McHale J, Ravi N, et al. Successful use of recombinant FVIIa (Novoseven) in the management of intractable post-surgical intra-abdominal haemorrhage (Letter). Br J Haematol 1999; 107: 677-8.

13 Tobias JD. Synthetic factor VIIa to treat dilutional coagulopathy during posterior spinal fusion in two children. Anesthesiology 2002; 96: 1522-5.

14 Svartholm E, Annerhagen V, Lanne T. Treatment of bleeding in severe necrotizing pancreatitis with recombinant factor VIIa (Letter). Anesthesiology 2002; 96: 1528.

15 Friederich PW, Henny CP, Messelink EJ, et al. Effect of recombinant activated factor VII on perioperative blood loss in patients undergoing retropubic prostatectomy: a double-blind placebo-controlled randomised trial. Lancet 2003; 361: 201-5.

16 Shapiro AD, Gilchrist GS, Hoots WK, Cooper HA, Gastineau DA. Prospective, randomised trial of two doses of rFVIIa (NovoSeven) in haemophilia patients with inhibitors undergoing surgery. Thromb Haemost 1998; 80: 773-8.

17 Mauser-Brunschoten EP, Koopman MM, de Goede-Bolder $A D$, et al. Efficacy of recombinant factor VII administered by continuous infusion to haemophilia patients with inhibitors. Haemophilia 2002; 8: 649-56.

18 Weiskopf $R B$. Intraoperative use of recombinant activated coagulation factor VII (Editorial). Anesthesiology 2002; 96: 1287-9.

19 Porte RJ, Leebeek FW. Pharmacological strategies to decrease transfusion requirements in patients undergoing surgery. Drugs 2002; 62: 2193-211.

20 Eikelboom JW, Bird R, Blythe D, et al. Recombinant activated factor VII for the treatment of life-threatening haemorrhage. Blood Coagul Fibrinolysis 2003; 14: 713-7.

21 Markiewicz M, Kalicinski P, Kaminski A, et al. Acute coagulopathy after reperfusion of the liver graft in children correction with recombinant activated factor VII. Transplant Proc 2003; 35: 2318-9.

22 Surudo T, Wojcicki M, Milkiewicz P, et al. Rapid correction of prothrombin time after low-dose recombinant factor VIIa in patients undergoing orthotopic liver transplantation. Transplant Proc 2003; 35: 2323-5.

23 Siegel LJ, Gerigk L, Tuettenberg J, Dempfle CE, Scharf J, Fiedler F. Cerebral sinus thrombosis in a trauma patient after recombinant activated factor VII infusion. Anesthesiolgy 2004; 100: 441-3.

24 O'Connell NM, Perry DJ, Hodgson AJ, O'Shaughnessy DF, Laffan MA, Smith OP. Recombinant FVIIa in the management of uncontrolled hemorrhage. Transfusion 2003; 43: 1711-6. 